\title{
Residual-stress relaxation mechanism and model description of 5052H32 Al alloy spun ellipsoidal heads during annealing treatment
}

\author{
Yong-Cheng Lin ${ }^{1}$ (D) Jiang-Shan Zhu ${ }^{1} \cdot$ Jia-Yang Chen ${ }^{1} \cdot$ Jun-Quan Wang1
}

Received: 14 January 2021 / Revised: 26 April 2021 / Accepted: 9 July 2021/Published online: 26 September 2021

(C) The Author(s) 2021

\begin{abstract}
Marginal-restraint mandrel-free spinning is an advanced technology for manufacturing ellipsoidal heads with large diameter-thickness ratios. Nevertheless, the spinning-induced residual stress, which greatly influences the in-service performance of spun heads, should be removed. In this study, the effects of annealing on the residual-stress relaxation behavior of $5052 \mathrm{H} 32$ aluminum alloy spun heads were investigated. It is found that the residual stress first rapidly decreases and then remains steady with the increase in annealing time at the tested annealing temperatures. The relaxation of the residual stress becomes increasingly obvious with the increase in annealing temperature. When the annealing temperature is less than $220{ }^{\circ} \mathrm{C}$, there are no obvious changes in grain size. Moreover, the spinning-induced dislocations are consumed by the static recovery behavior, which decreases the residual stress during annealing. When the annealing temperature is approximately $300{ }^{\circ} \mathrm{C}$, the broken grains transform into equiaxed grains. In addition, static recrystallization and recovery behaviors occur simultaneously to promote the relaxation of the residual stress. Considering the different stress relaxation mechanisms, a model based on the Zener-Wert-Avrami equation was established to predict the residual-stress relaxation behavior. Finally, the optimized annealing temperature and time were approximately $300{ }^{\circ} \mathrm{C}$ and $30 \mathrm{~min}$, respectively.
\end{abstract}

Yong-Cheng Lin

yclin@csu.edu.cn

1 School of Mechanical and Electrical Engineering, Central South University, Changsha 410083, People's Republic of China
Keywords Spinning $\cdot$ Residual stress $\cdot$ Annealing treatment $\cdot$ Microstructure evolution $\cdot$ Relaxation mechanism

\section{Introduction}

With the rapid development of the aerospace industry, large-scale high-performance curved components are increasingly required. The spinning process is usually employed to manufacture integral curved heads owing to its remarkable flexibility and efficiency [1-5]. Usually, the spinning parameters can be optimized to improve the forming accuracy and microstructures of spun parts [6-10]. However, owing to the dramatic plastic deformation in the spinning process, the generation of residual stress in spun heads is inevitable [11-13]. In particular, tensile residual stress causes deterioration of service performance and life $[14,15]$. Therefore, it is essential to study the distribution characteristics and relief strategies of the residual stress in spun components [16].

Many studies on the relaxation strategies of residual stress in alloy components have been conducted. For instance, Hu and Wang [17] and Chang et al. [18] studied the influence of solution treatment on spun parts; they found that the residual stress could be eliminated and the grain size refined. Hui et al. [19] revealed that annealing treatment promoted the formation of equiaxed grains in a $\mathrm{Cu}-\mathrm{Sn}$ alloy spun part. Tsivoulas et al. [20] found that the residual stress decreased in $\mathrm{Cr}-\mathrm{Mo}-\mathrm{V}$ steel tubes during heat treatment. Yu et al. [21] investigated the influence of spinning parameters on the stress distribution and damage of hemispherical Al alloy parts, and optimized spinning parameters were obtained. Lin et al. [22] studied the effects of staggered spinning parameters on the microstructures 
and residual-stress distribution of spun cylindrical parts. Zhou et al. [23] discovered that the residual relaxation behavior mainly occurred during the initial $20 \mathrm{~min}$ of exposure, and the extent of relaxation increased with heating temperature. Other studies have shown that the residual-stress relaxation in the annealing process occurs from $20 \mathrm{~min}$ to $40 \mathrm{~min}[24,25]$, and then the residual stress remains approximately stable. In addition, many researchers have established different models to describe residualstress relaxation behavior. Xie et al. [26] developed a finite-element model to predict residual-stress relaxation behavior. Sembiring et al. [27] provided intelligent models for describing the residual-stress relaxation behavior of superalloys. Jagtap and Chason [28] developed a stress relaxation kinetic model to depict the stress recovery and relaxation behaviors in polycrystalline thin films. Juijerm and Altenberger [29] demonstrated the relaxation behavior of residual stress by the Zener-Wert-Avrami formula. The Zener-Wert-Avrami model is widely used to describe the residual-stress relaxation behavior of aluminum alloys $[30,31]$ and other alloys [32, 33] accurately in the heat treatment process.

In Refs. [34, 35], the spinning parameters have been optimized to improve the forming accuracy and microstructures of ellipsoidal heads. However, the spinning-induced residual stress still significantly influences the in-service performance of spun heads. Although some research has been conducted on the residual-stress relaxation behavior in alloy components, there have been few efforts to develop residual-stress relaxation strategies of $5052 \mathrm{H} 32$ aluminum alloy spun heads. However, this issue is extremely important for the industrial production of thinwalled spun alloy components.

In this work, an attempt was made to reduce the residual stress by annealing treatment, and the effects of annealing treatment on the residual-stress relaxation behavior and microstructures of $5052 \mathrm{H} 32$ aluminum alloy spun heads were studied in detail. The residual-stress relaxation mechanisms were also analyzed. A model was developed to describe the residual-stress relaxation features of the spun ellipsoidal head during the annealing treatment. Finally, optimized annealing parameters were obtained.

\section{Material and experiments}

\subsection{Spun heads and annealing scheme}

In this study, a 5052H32 aluminum alloy was used, and its chemical composition (mass fraction, \%) is shown in Table 1. First, the spun heads were manufactured from $5052 \mathrm{H} 32$ aluminum alloy square plates (the initial width and thickness were $400 \mathrm{~mm}$ and $1 \mathrm{~mm}$, respectively) by
Table 1 Chemical compositions of 5052H32 Al alloy (mass fraction, $\%)$

\begin{tabular}{llllllll}
\hline $\mathrm{Mg}$ & $\mathrm{Si}$ & $\mathrm{Fe}$ & $\mathrm{Cu}$ & $\mathrm{Mn}$ & $\mathrm{Cr}$ & $\mathrm{Zn}$ & $\mathrm{Al}$ \\
\hline 2.47 & 0.05 & 0.27 & 0.01 & 0.05 & 0.25 & 0.01 & $\mathrm{Bal}$. \\
\hline
\end{tabular}

marginal-restraint mandrel-free spinning, as shown in Fig. 1a. A detailed spinning process has been reported previously $[34,35]$. A two-pass spinning process was used in this study. In the first pass, the forming angle, roller installation angle, feed ratio, roller fillet radius, and spindle speed were approximately $40^{\circ}, 45^{\circ}, 1.2 \mathrm{~mm} / \mathrm{r}, 6 \mathrm{~mm}$, and $300 \mathrm{r} / \mathrm{min}$, respectively. In the second pass, the angle between passes was $10^{\circ}$, and the other spinning parameters were the same as those in the first pass. Annealing experiments were then carried out on the spun heads. The following annealing temperatures $\left(140{ }^{\circ} \mathrm{C}, 220{ }^{\circ} \mathrm{C}\right.$, and 300 ${ }^{\circ} \mathrm{C}$ ) and annealing times (10-60 min) were designed, as depicted in Fig. 1b.

\subsection{Residual-stress measurement}

The basic principle of X-ray diffraction (XRD) is mainly to use the interaction of the X-ray beam and material lattice to measure the lattice distance change of the crystal plane caused by residual stress. The residual stress was measured using the XRD equipment in this study; the measuring system provided concrete residual-stress values. XRD test equipment produced by the Proto Company (Canada) was used to measure the residual stress, as shown in Fig. 2a. Cr target was selected, and the Gaussian method was used as the peak positioning technology. The test voltage was 25 $\mathrm{kV}$, and the tube current was $5 \mathrm{~mA}$. The exposure time was 2-4 s, and the number of exposures was seven. The beta angle was between $-20^{\circ}$ and $20^{\circ}$, and the Bragg angle was set to $156.31^{\circ}$. In addition, there were four measuring points on the external surface, and they were evenly selected in the steady spinning regions of the spun heads, as shown in Fig. 2b. The residual stresses in the generatrix and circumferential directions were measured three times each.

\subsection{Microstructure observations}

To investigate the effects of the annealing parameters on the microstructures of the spun heads, electron backscatter diffraction analysis was performed. The specimens were cut from the spun head, ground with waterproof abrasive paper, and polished by double-jet electropolishing with $10 \% \mathrm{HClO}_{4}$ and $90 \% \mathrm{CH}_{3} \mathrm{OH}$ at $-30{ }^{\circ} \mathrm{C}$. Microstructures on the external surfaces of the spun heads were observed. 


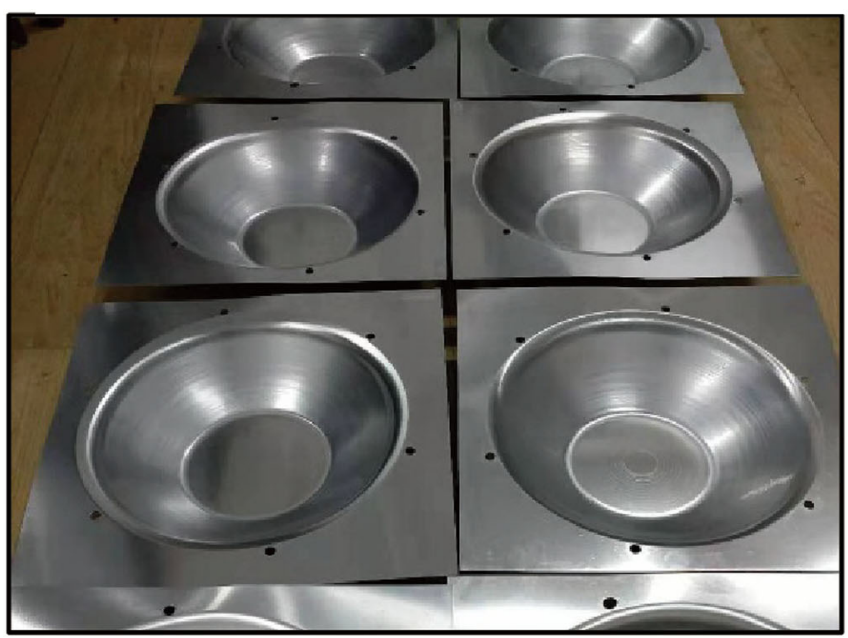

(a)

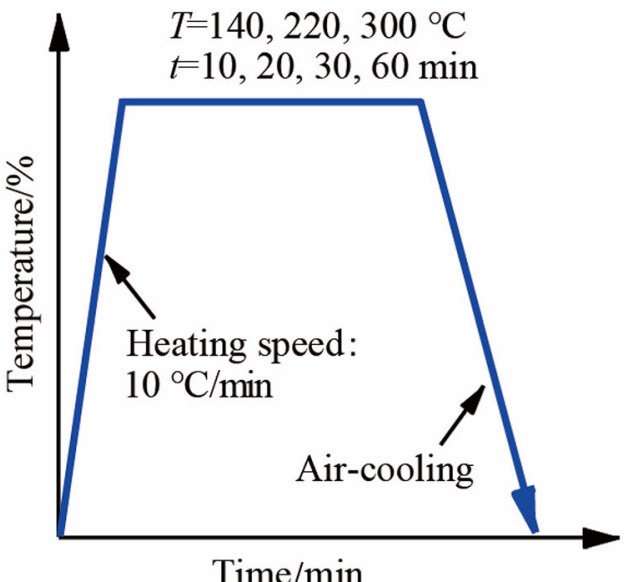

(b)

Fig. 1 Spun heads and annealing scheme a the spun heads, $\mathbf{b}$ the annealing scheme

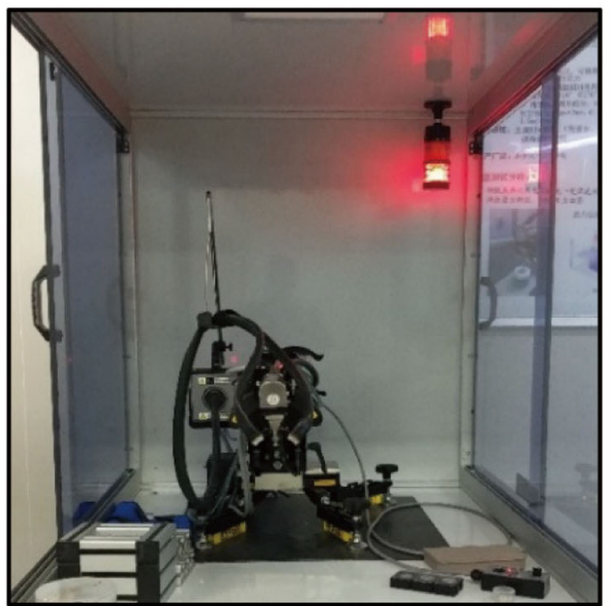

(a)

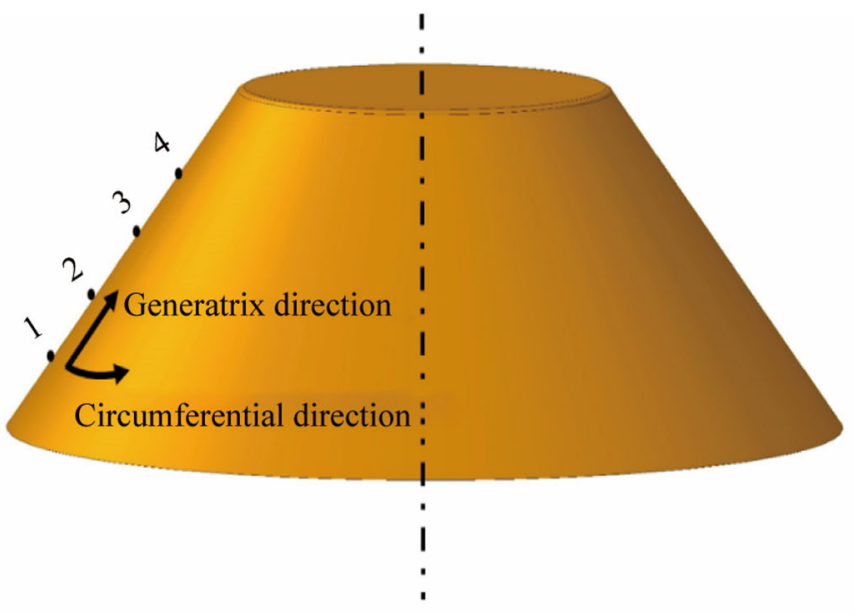

(b)

Fig. 2 Measurement of residual stress a XRD test equipment, $\mathbf{b}$ measuring position

\section{Results and discussion}

\subsection{Effects of annealing parameters on the residual stress}

Figure 3a shows the initial residual stress in the generatrix and circumferential directions of the spun heads. The residual stress remained approximately stable in both directions because the spinning deformation behavior was stable in the steady spinning region. However, the residual stress in the generatrix direction was obviously greater than that in the circumferential direction. This is because the roller feeds along the generatrix direction, and the material flow is more intense than that along the circumferential direction. Therefore, the degree of plastic deformation is relatively larger along the generatrix direction. Figures $3 b$ and c depict the effects of the annealing parameters on the residual stress in the generatrix and circumferential directions, respectively. The residual stress in both directions rapidly decreased in the first $10 \mathrm{~min}$ and then slowly decreased. Furthermore, the residual stress remained approximately stable after annealing for $30 \mathrm{~min}$. Meanwhile, the residual-stress relaxation law was consistent in both directions during the annealing treatment and mainly occurred in the early annealing stage.

Figures $3 \mathrm{~d}$ and e show the effects of annealing temperature on the relaxation percentage of residual stress for annealing times of $10 \mathrm{~min}$ and $30 \mathrm{~min}$. The relaxation degree of the residual stress in both directions clearly increases with increasing annealing temperature. As depicted in Fig. 3e, when the annealing temperature was $140{ }^{\circ} \mathrm{C}$, the static recovery behavior was inadequate. There 


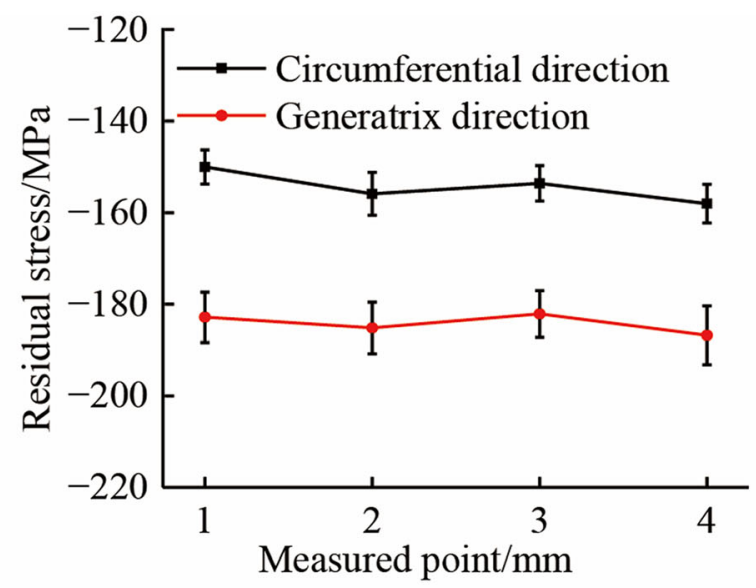

(a)

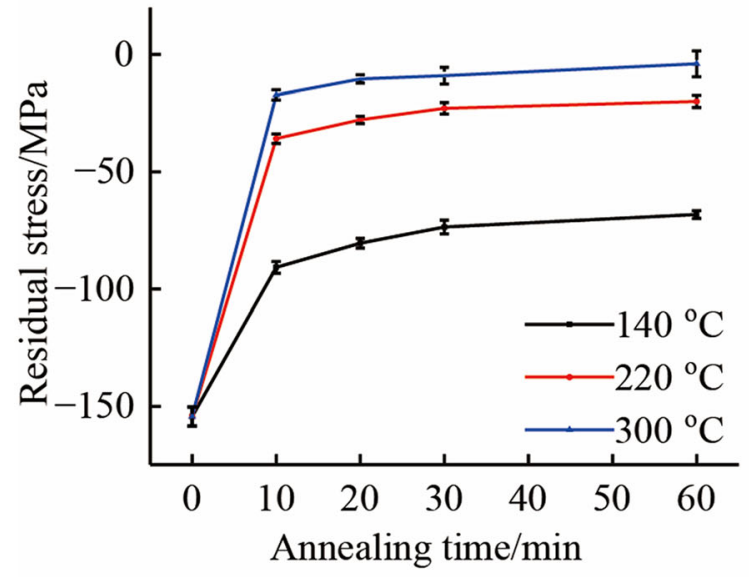

(b)

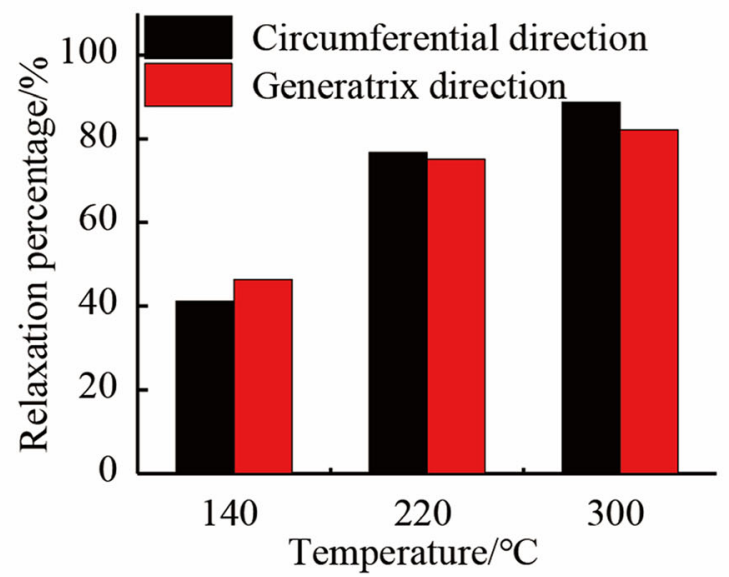

(d)

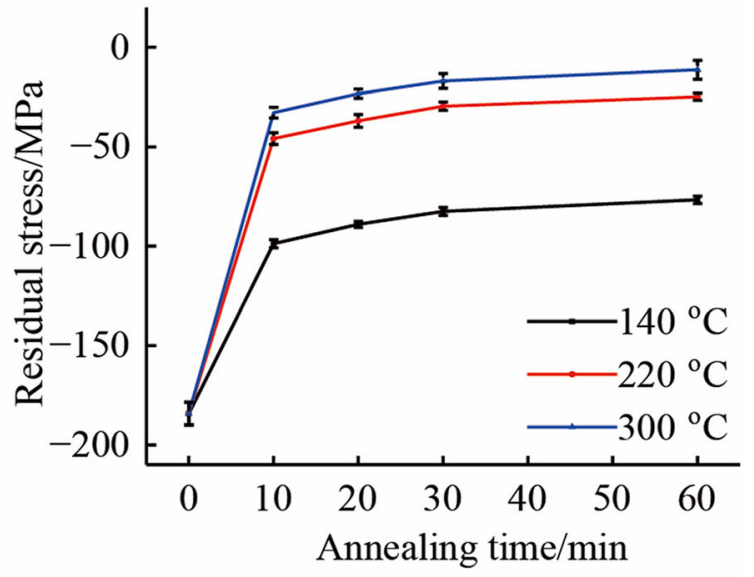

(c)

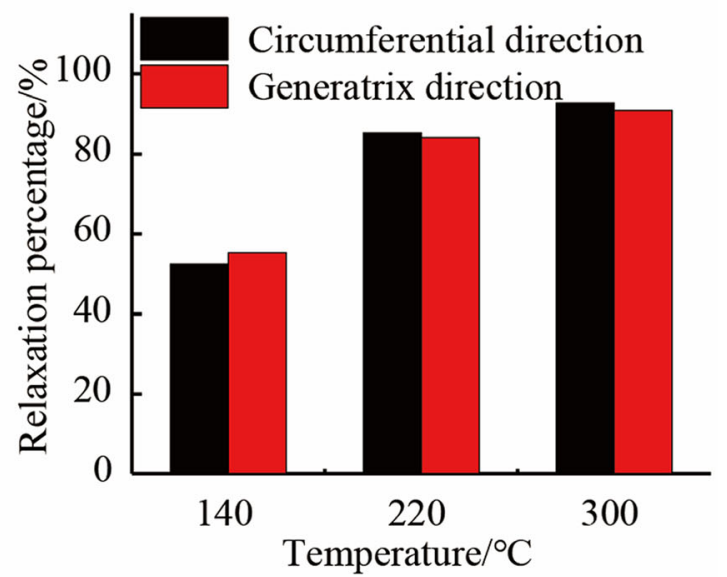

(e)

Fig. 3 Effects of annealing time and temperature on a the initial residual stress, b the residual stress in the circumferential direction, $\mathbf{c}$ the residual stress in the generatrix direction, $\mathbf{d}$ the relaxation percentage of residual stress at 10 min, $\mathbf{e}$ the relaxation percentage of residual stress at $30 \mathrm{~min}$

were still considerable dislocations in the spun head. The relaxation percentages of the residual stress in the circumferential and generatrix directions were $52.32 \%$ and
$55.2 \%$, respectively. When the annealing temperature was $220{ }^{\circ} \mathrm{C}$, the relaxation percentages of residual stress in the two directions were $85.18 \%$ and $83.98 \%$, respectively, 


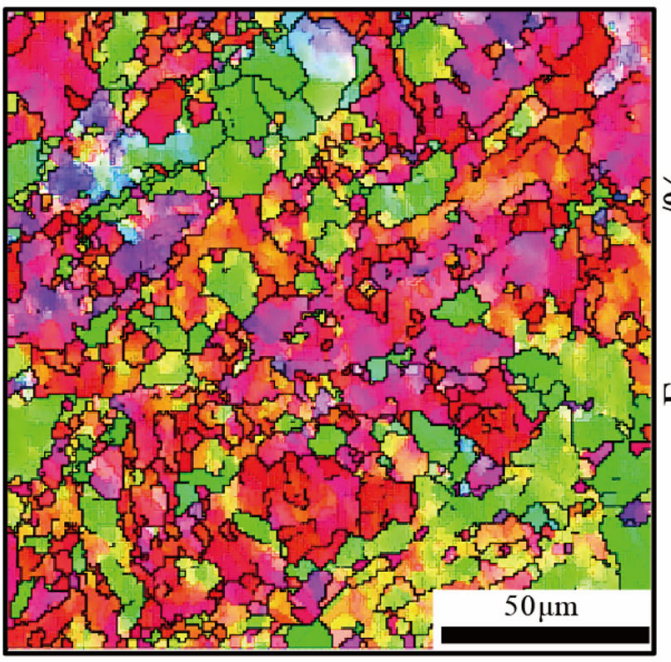

(a)

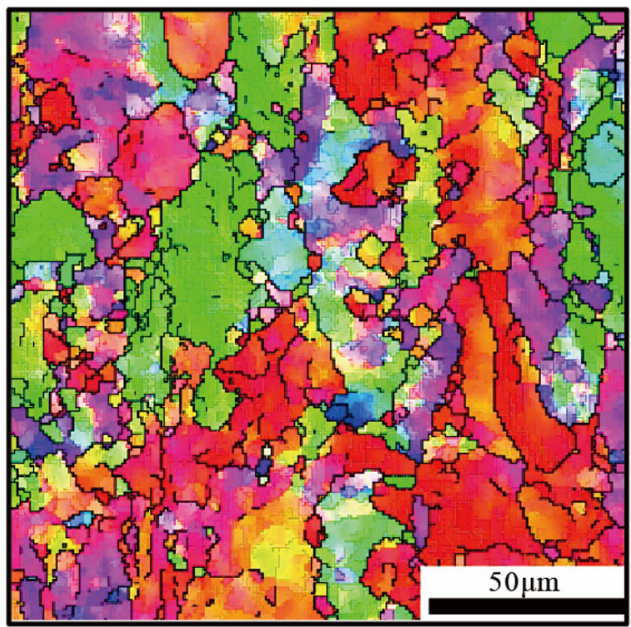

(c)

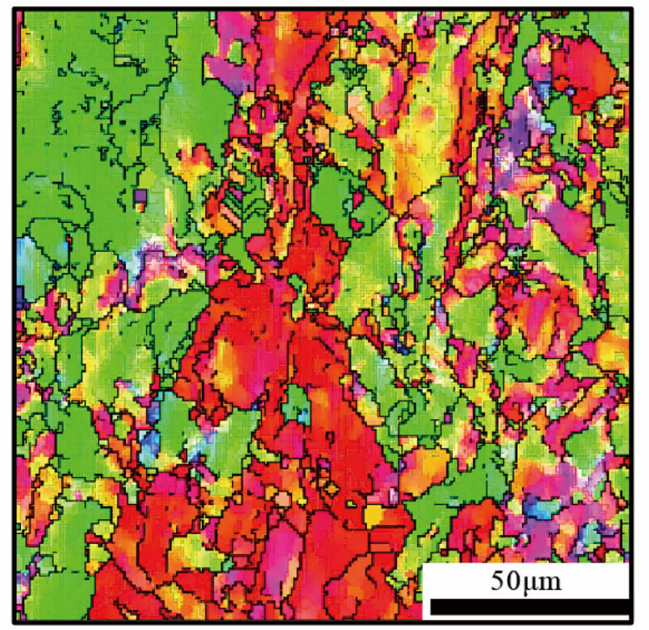

(e)

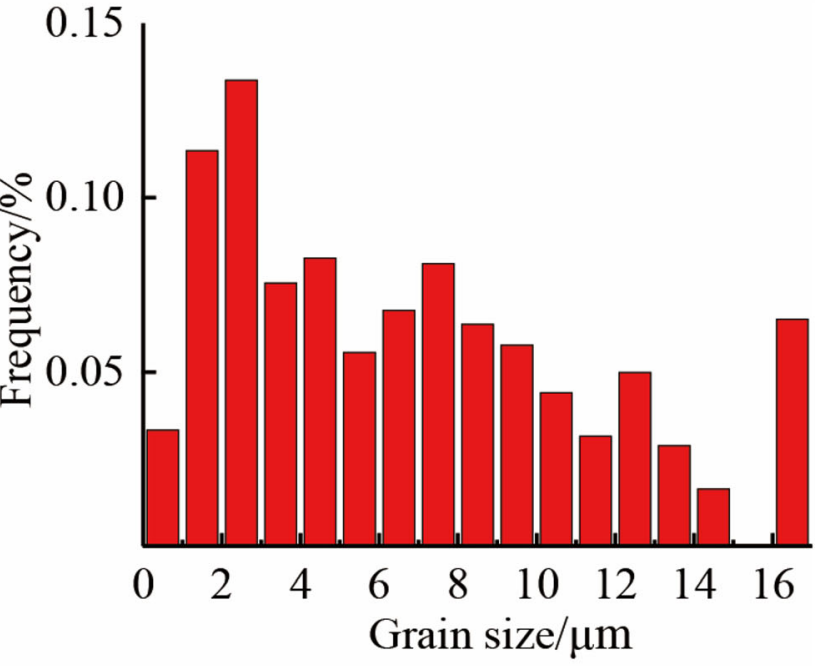

(b)

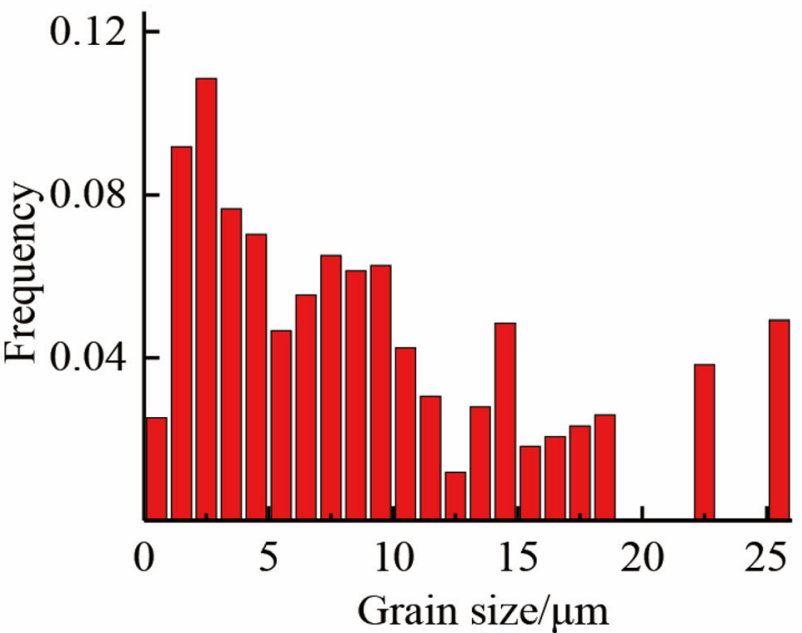

(d)

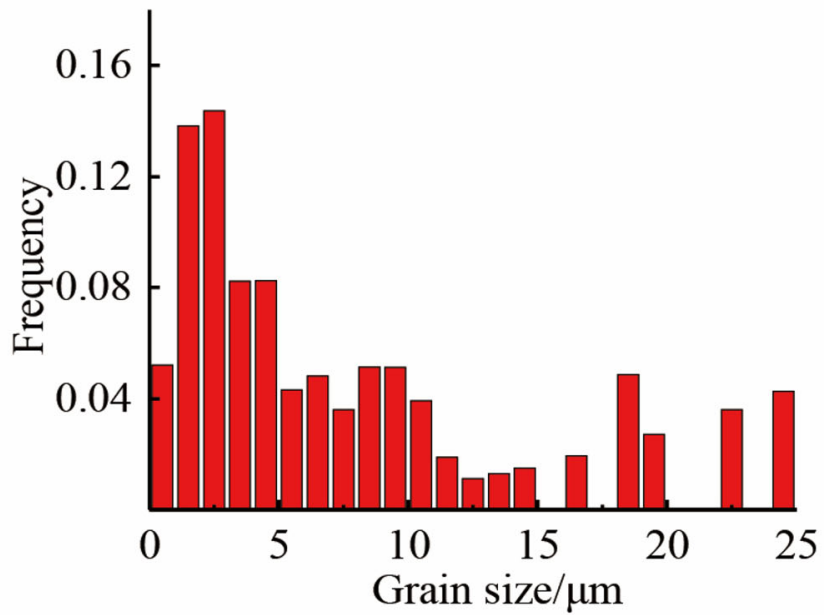

(f)

Fig. 4 Microstructures and grain size of the spun heads a, b initial, c, d $140{ }^{\circ} \mathrm{C}, 30 \mathrm{~min}, \mathbf{e}, \mathbf{f} 220^{\circ} \mathrm{C}, 30 \mathrm{~min}$ 


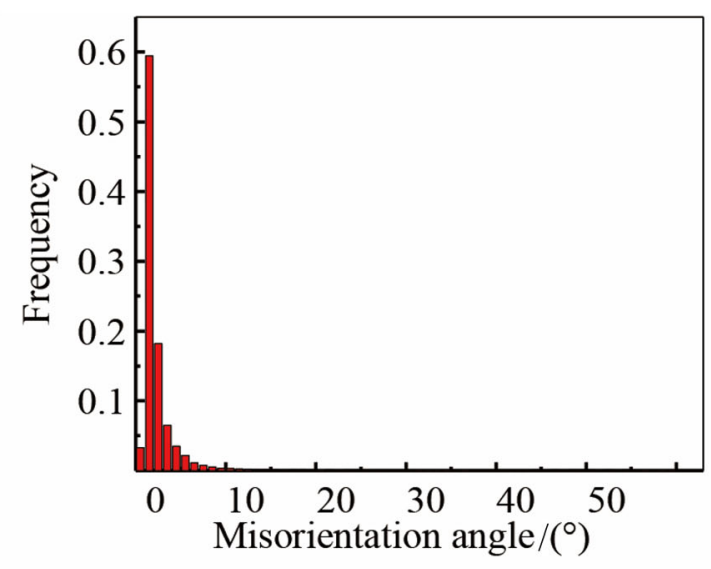

(a)

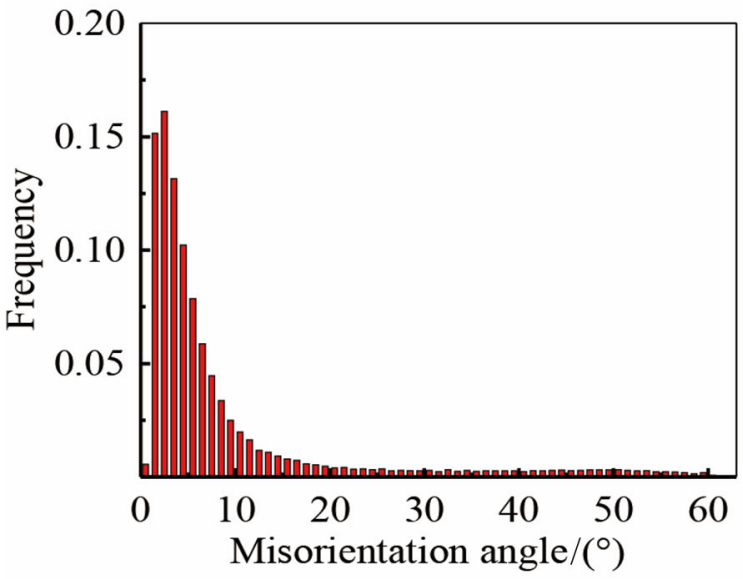

(c)

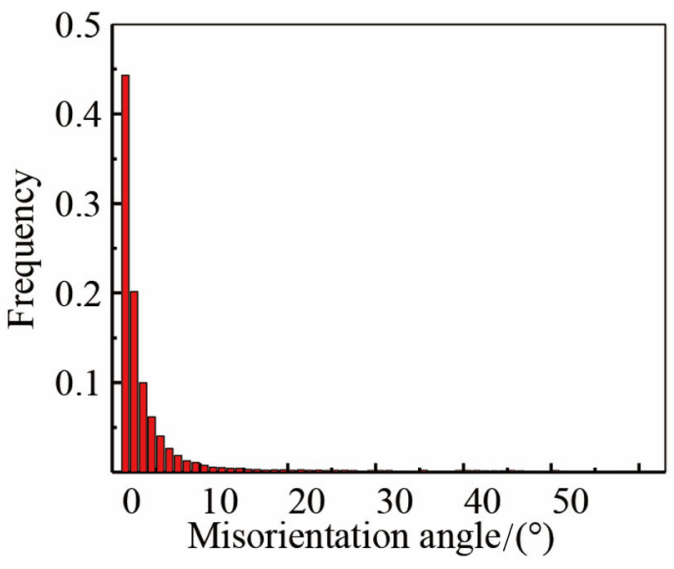

(b)

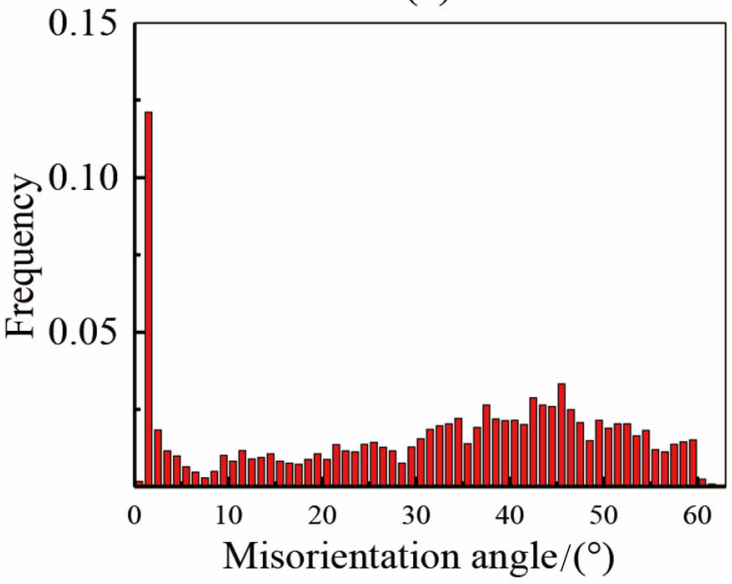

(d)

Fig. 5 Misorientation angle distribution of a the unannealed spun alloy, b the annealed spun alloy at $220{ }^{\circ} \mathrm{C}$ for 30 min, $\mathbf{c}$ the annealed spun alloy at $300{ }^{\circ} \mathrm{C}$ for $10 \mathrm{mins}, \mathbf{d}$ the annealed spun alloy at $300{ }^{\circ} \mathrm{C}$ for $60 \mathrm{~min}$

because the raised temperature enhanced the static recovery behavior. Furthermore, when the annealing temperature increased to $300{ }^{\circ} \mathrm{C}$ (above the recrystallization temperature of $260{ }^{\circ} \mathrm{C}$ ), the relaxation percentages of residual stress in the two directions were $92.67 \%$ and $90.80 \%$, respectively. Static recovery and recrystallization $[36,37]$ occurred simultaneously during annealing. Therefore, the relaxation degree of the residual stress was relatively adequate at approximately $300{ }^{\circ} \mathrm{C}$. At annealing temperatures of $140{ }^{\circ} \mathrm{C}$ and $220{ }^{\circ} \mathrm{C}$, the annealing treatment aggravated the atomic diffusion and dislocation rearrangement, inducing thermal recovery and reduced residual stress. When the annealing temperature was $300{ }^{\circ} \mathrm{C}$, recrystallization and recovery behavior occurred simultaneously to consume dislocations and deformation storage energy further. Subsequently, the residual stress decreased. Therefore, the suitable annealing treatment parameters were approximately $300{ }^{\circ} \mathrm{C}$ and $30-60 \mathrm{~min}$.

\subsection{Effects of annealing parameters on the microstructures}

Figures $4 \mathrm{a}$ and $\mathrm{b}$ depict the microstructures and grain size distribution of the spun heads before annealing, i.e., the slender microstructures are surrounded by many broken grains. Figures $4 \mathrm{c}$ and e show the microstructures of the spun heads annealed for $30 \mathrm{~min}$ at $140{ }^{\circ} \mathrm{C}$ and $220{ }^{\circ} \mathrm{C}$, respectively. Clearly, there are some slender and broken grains, and the size is distributed between $0.5 \mu \mathrm{m}$ and 25.5 $\mu \mathrm{m}$. Furthermore, small grains were dominant. There were no obvious differences in the microstructures of the unannealed and annealed alloys. Figure 5 shows the distribution of the misorientation angles for different annealing parameters. The misorientation angle of the spun alloy annealed for $30 \mathrm{~min}$ at $220^{\circ} \mathrm{C}$ was almost the same as that of the unannealed spun alloy. Both were dominated by the low-angle grain boundary within $0^{\circ}-10^{\circ}$. Furthermore, there was no obvious recrystallization at lower 


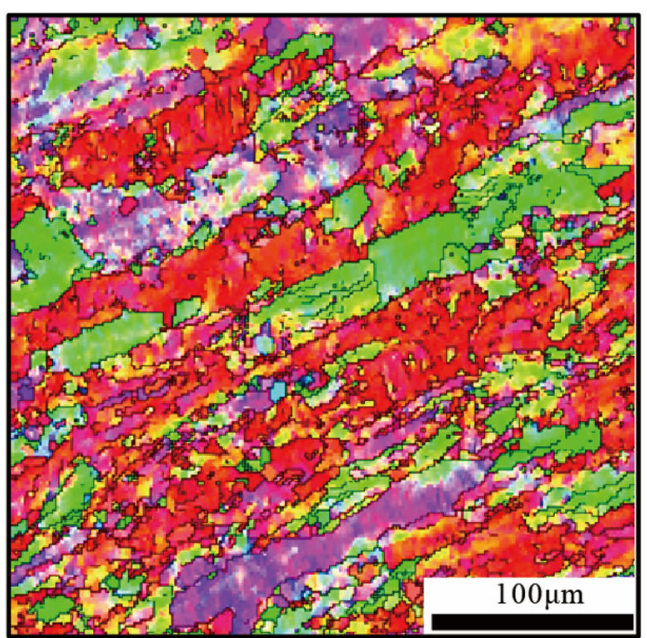

(a)

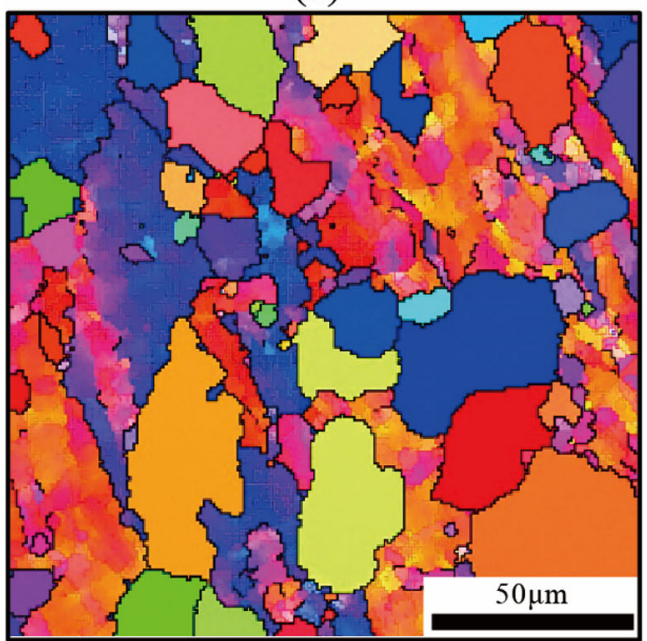

(c)

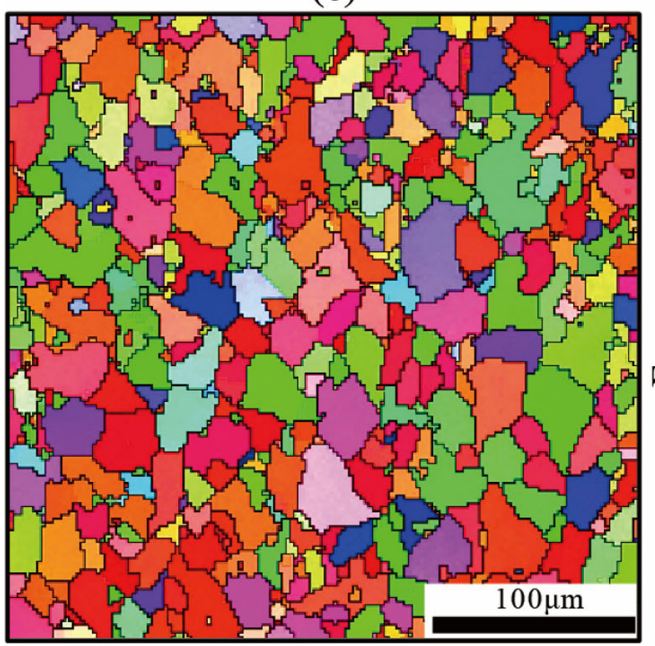

(e)

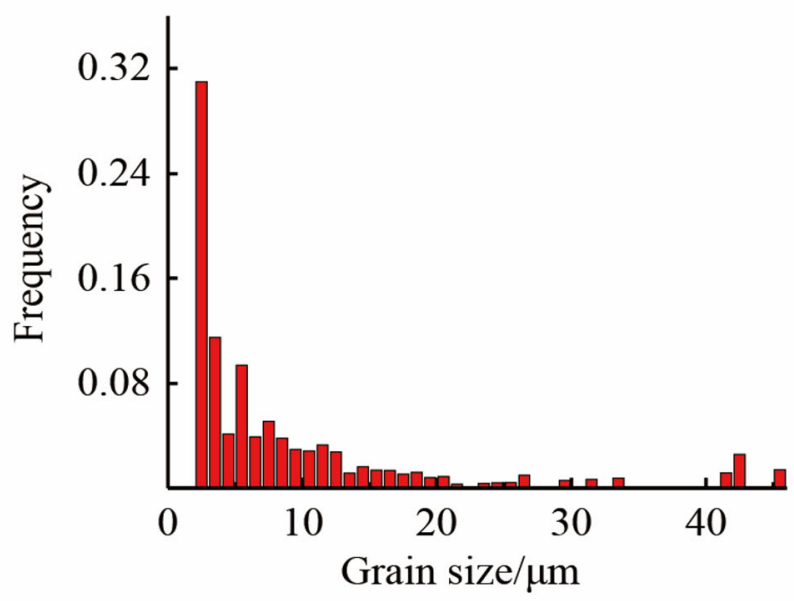

(b)

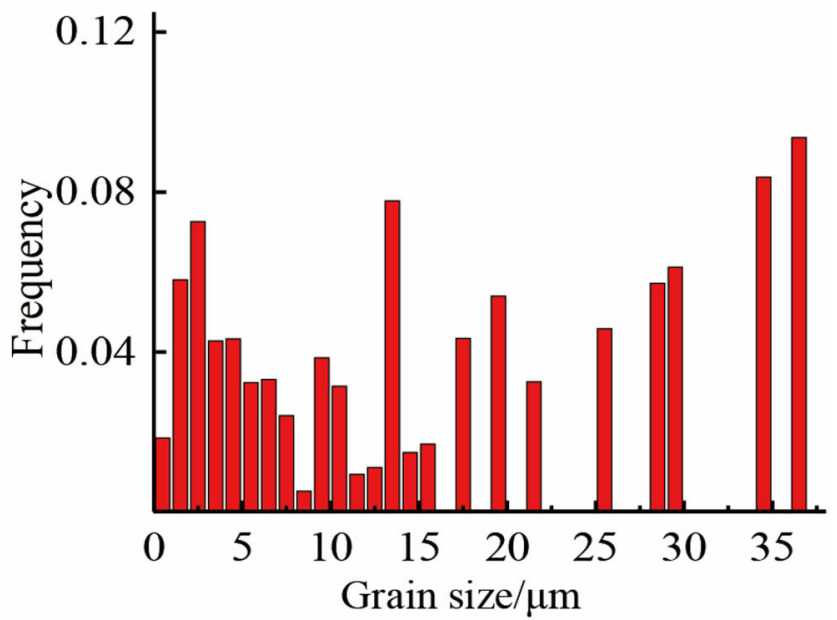

(d)

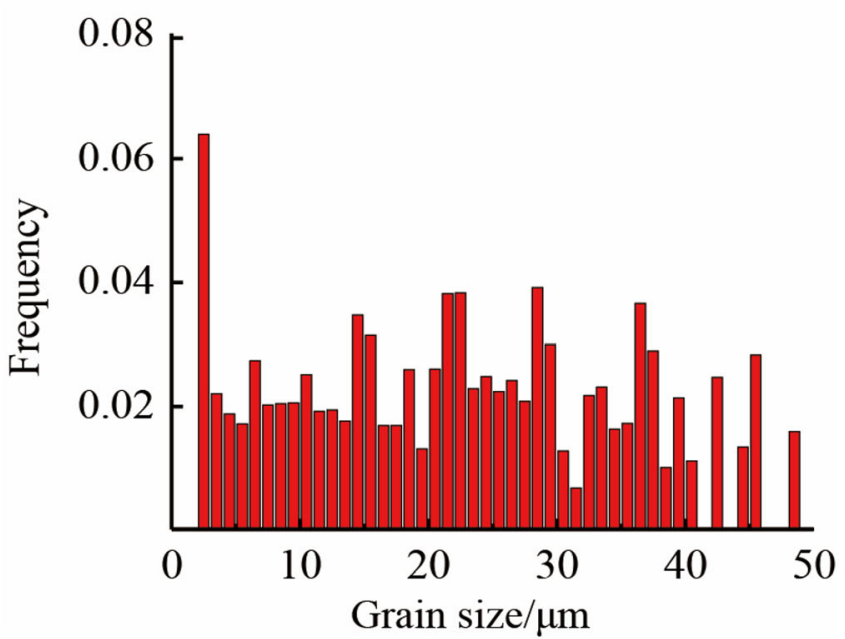

(f)

Fig. 6 Microstructures and grain size distribution of the annealed spun alloy at $300^{\circ} \mathrm{C}$ for $\mathbf{a}, \mathbf{b} 10 \mathrm{~min}, \mathbf{c}, \mathbf{d ~} 30 \mathrm{~min}, \mathbf{e}, \mathbf{f} 60 \mathrm{~min}$ 
temperatures. Therefore, the relaxation of the residual stress mainly relies on static recovery at lower annealing temperatures.

Figure 6 shows the microstructures and grain size distributions of the spun alloy annealed at $300{ }^{\circ} \mathrm{C}$. When the annealing time was $10 \mathrm{~min}$, as shown in Fig. 5c, a highangle grain boundary (HAGB) gradually appeared. Meanwhile, as Figs. 6a and b show, there were still some elongated or broken grains, and some fine recrystallized grains were found near the grain boundaries. The proportion of small grains was clearly larger than that of the unannealed spun alloy. Therefore, the static recrystallization and recovery behaviors jointly promote the relaxation of the residual stress. When the annealing time was $30 \mathrm{~min}$, as shown in Figs. 6c and d, static recrystallization behavior further occurred, and the number of recrystallized nuclei gradually grew. Therefore, the number of recrystallized grains increased, and the broken grains gradually disappeared during annealing. When the annealing time was increased to $60 \mathrm{~min}$, as shown in Figs. 6e and f, the elongated or broken grains were completely replaced by equiaxed recrystallization grains. In addition, grain growth was very prominent. As shown in Fig. 5d, for spun alloy annealed at $300{ }^{\circ} \mathrm{C}$ for $60 \mathrm{~min}$, the HAGBs were dominant, and the mean misorientation angle was $31.5^{\circ}$. This indicates sufficient recrystallization behavior. Therefore, the residual-stress relaxation behavior completely occurs at elevated annealing temperatures.

\subsection{Effects of annealing parameters on the dislocation density}

The residual stress obtained by XRD tests can be converted into dislocation density, according to Eqs. (1)-(3) [36, 37].

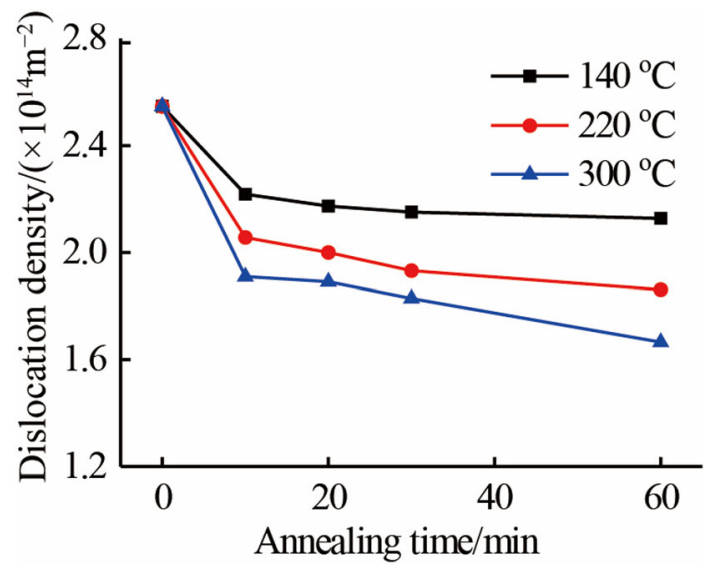

Fig. 7 Effects of annealing time and temperature on the dislocation density of spun heads
$D=\frac{\lambda}{\beta_{\mathrm{C}}^{\mathrm{f}} \cos \theta}$,

$\varepsilon=\frac{\beta_{\mathrm{G}}^{\mathrm{f}}}{4 \tan \theta}$,

$\rho=\frac{2 \sqrt{3}\left\langle\varepsilon^{2}\right\rangle^{1 / 2}}{|\boldsymbol{b}| D_{1}}$,

where $D$ represents microcrystal size, $\lambda$ the wavelength, $\beta_{\mathrm{C}}^{\mathrm{f}}$ the integral breadth, $\theta$ the Bragg angle. $\varepsilon$ represents microstrain; $\beta_{\mathrm{G}}^{\mathrm{f}}$ is the integral breadth. $\rho$ represents dislocation density; $D_{1}$ is the apparent crystallite or domain size; $\boldsymbol{b}$ represents the Burgers vector, which is $0.268 \mathrm{~nm}$ for $\mathrm{Al}$ alloys [38].

Figure 7 depicts the effects of the annealing time and temperature on the dislocation density. The dislocation density rapidly decreased within the first $10 \mathrm{~min}$ and then remained stable at the tested annealing temperatures. This is because most of the spinning-induced dislocations were consumed by the recovery or recrystallization behavior in the early annealing stage, which caused a rapid decrease in the dislocation density. However, the inherent remaining dislocations were difficult to consume. Therefore, the change in dislocation density was slow at the later annealing stage. This was consistent with the relaxation law of residual stress, which was discussed in Sects. 3.1 and 3.2. In addition, the dislocation density decreased with increasing annealing temperature. Meanwhile, the dislocation was further consumed by the static recrystallization behavior at an annealing temperature of $300{ }^{\circ} \mathrm{C}$. Therefore, the dislocation density clearly decreased.

Figure 8 shows the kernel average misorientation (KAM) maps and the distribution of the local misorientation angle in the spun alloy annealed at $300{ }^{\circ} \mathrm{C}$. A large KAM value indicates high dislocation density [38]. Figures $8 \mathrm{a}$ and $\mathrm{b}$ showed that the local misorientation angle was densely distributed in the range $1^{\circ}-3.5^{\circ}$ for the unannealed spun alloy, i.e., there was a high dislocation density. After annealing for $30 \mathrm{~min}$ (see Figs. $8 \mathrm{c}$ and d), the local misorientation angle was mainly distributed in the range $0.1^{\circ}-0.5^{\circ}$, but there was still a small amount of high local misorientation angle. This was because the majority of the dislocation density was consumed by the static recovery and recrystallization behaviors. Therefore, the dislocation density decreased as annealing progressed. When the annealing time was 60 min (see Figs. 8e and f), the dislocation density was further reduced. The local orientation angle was mainly distributed in the range $0.1^{\circ}$ $0.8^{\circ}$, i.e., the high dislocation density generated during spinning was almost eliminated. Hence, the change in the dislocation density agrees well with that of the residual stress. 


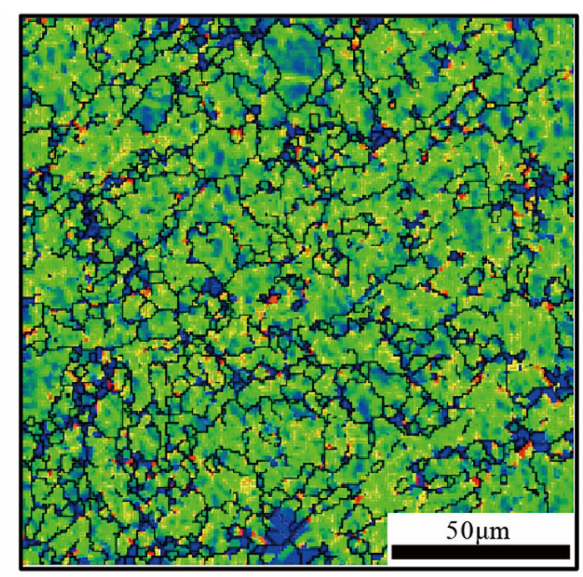

(a)

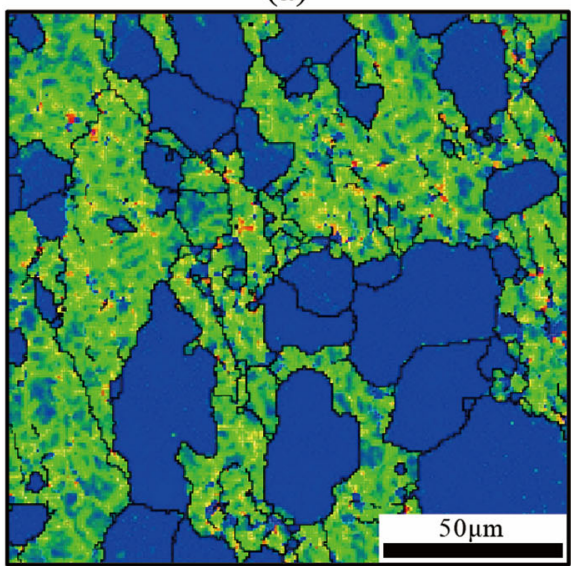

(c)

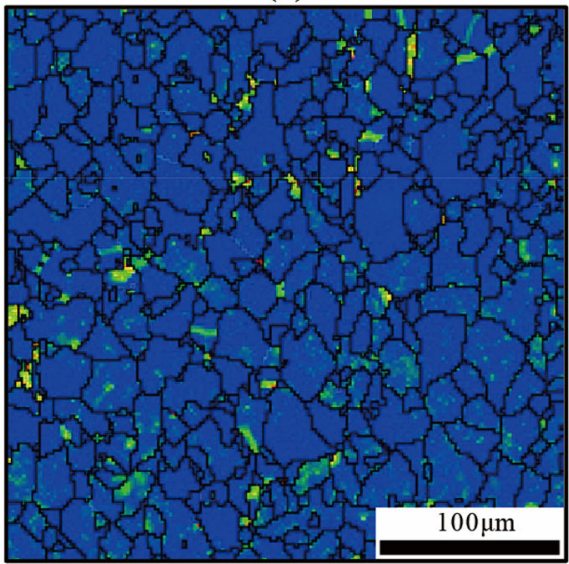

(e)

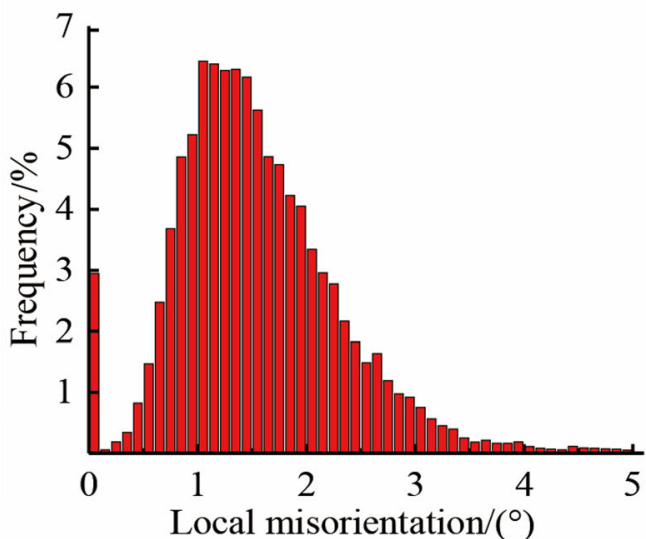

(b)

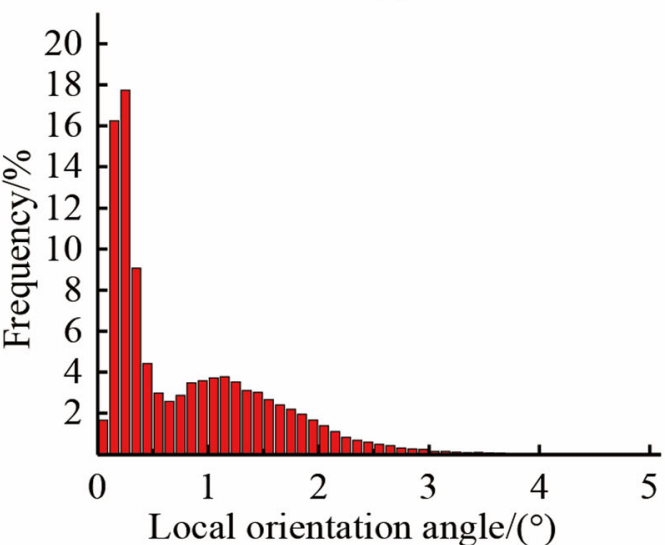

(d)

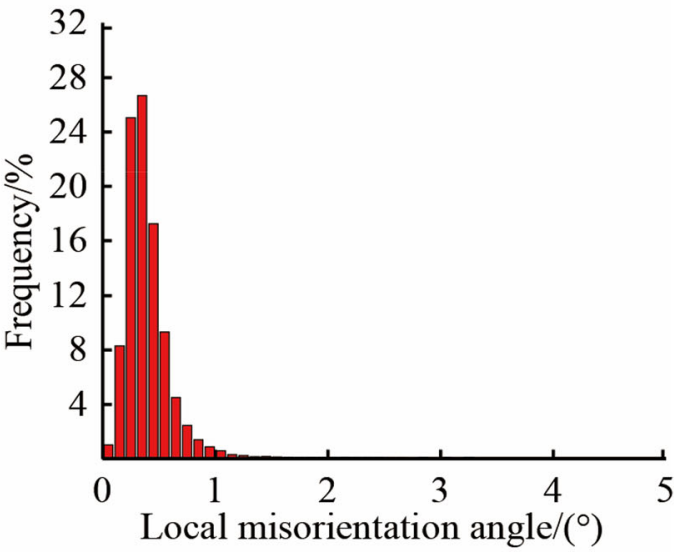

(f)

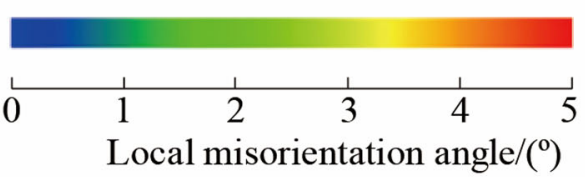

(g)

Fig. 8 KAM maps and distribution of local misorientation angle in annealed alloy at $300{ }^{\circ} \mathrm{C}$ for $\mathbf{a}, \mathbf{b}$ the unannealed alloy, $\mathbf{c}, \mathbf{d} 30 \mathrm{~min}, \mathbf{e}, \mathbf{f} 60$ min, $\mathbf{g}$ the color label of local misorientation 


\section{Residual-stress relaxation model}

\subsection{Establishment of the residual-stress relaxation model}

The residual-stress relaxation can be modeled using the Zener-Wert-Avrami equation [29]

$\frac{\sigma_{1}}{\sigma_{0}}=\exp \left(-(A t)^{m}\right)$

where $\sigma_{1}$ and $\sigma_{0}$ are the residual stresses of the annealed and unannealed alloys, respectively, $m$ a material constant related to the release mechanism of residual stress, $t$ the annealing time, and $A$ a function related to the material and annealing temperature, i.e.,

$A=B \exp \left(-\frac{\Delta H}{k T}\right)$,

where $B$ is a material constant and can be evaluated as 3.06 $\times 10^{12} \min ^{-1}$ for aluminum alloy [29], $k$ Boltzmann's constant, which is $8.617343 \times 10^{-5} \mathrm{eV} / \mathrm{K}, T$ the annealing temperature, and $\Delta H$ the activation enthalpy during the release process of the residual stress. Equation (6) is obtained by the logarithmic transformation of Eq. (4). The relationship between $\lg \left(-\ln \left(\sigma_{1} / \sigma_{0}\right)\right)$ and $\lg (t)$ is linear at a given temperature.

$\lg \left(-\ln \left(\frac{\sigma_{1}}{\sigma_{0}}\right)\right)=m \lg A+m \lg (t)$.

Figure 9 shows the distribution of $\lg \left(-\ln \left(\sigma_{1} / \sigma_{0}\right)\right)$ and $\lg (t)$ at different annealing temperatures. The relationship between $\lg \left(-\ln \left(\sigma_{1} / \sigma_{0}\right)\right)$ and $\lg (t)$ in the circumferential and generatrix directions of the spun heads can be well fitted by straight lines. This indicates that the relaxation behavior of the residual stress during the annealing process satisfies the Zener-Wert-Avrami equation. The slope of the fitting line represents the value of the material constant

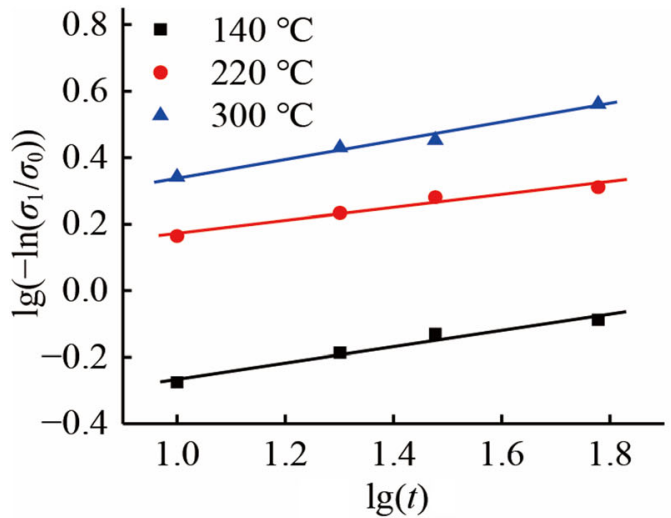

(a) $m$ in Eq. (6), and the activation enthalpy $\Delta H$ is obtained by regression analysis in combination with Eq. (5), as shown in Tables 2 and 3.

The aforementioned analysis demonstrates that the values of $m$ in the circumferential and generatrix directions at $300{ }^{\circ} \mathrm{C}$ are larger than those at $140{ }^{\circ} \mathrm{C}$ and $220{ }^{\circ} \mathrm{C}$. This shows that the relaxation mechanism of the residual stress at $300{ }^{\circ} \mathrm{C}$ is different from that at $140{ }^{\circ} \mathrm{C}$ and $220{ }^{\circ} \mathrm{C}$. Furthermore, this conclusion is consistent with previous experimental findings. Therefore, according to the different relaxation mechanisms of residual stress, static recovery, and recrystallization mechanisms, the model can be revised in the following format. Here, $m$ and $\Delta H$ are the average values in both directions.

$\left\{\begin{array}{l}\sigma_{1}=\sigma_{0} \exp \left(-(B t)^{m} \exp \left(-\frac{n}{(T+273.15)}\right)\right), \\ m=0.20959, n=2961.18 \quad\left(T \leq 260^{\circ} \mathrm{C}\right), \\ m=0.27404, n=4499.83 \quad\left(T>260^{\circ} \mathrm{C}\right) .\end{array}\right.$

Table 2 Values of $m$ and $\Delta H$ of circumferential residual stress

\begin{tabular}{lll}
\hline Temperature $/{ }^{\circ} \mathrm{C}$ & $m$ & $\Delta H / \mathrm{eV}$ \\
\hline 140 & 0.245 & 1.20 \\
220 & 0.192 & 1.23 \\
300 & 0.276 & 1.40 \\
\hline
\end{tabular}

Table 3 Values of $m$ and $\Delta H$ of generatrix residual stress

\begin{tabular}{lll}
\hline Temperature $/{ }^{\circ} \mathrm{C}$ & $m$ & $\Delta H / \mathrm{eV}$ \\
\hline 140 & 0.193 & 1.19 \\
220 & 0.209 & 1.25 \\
300 & 0.272 & 1.43 \\
\hline
\end{tabular}

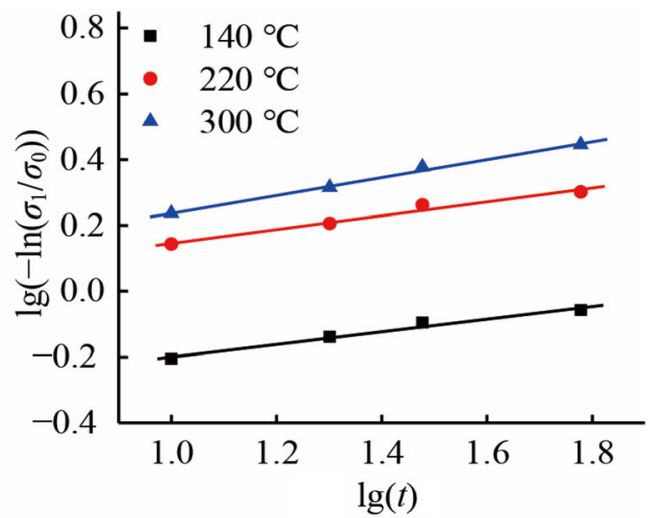

(b)

Fig. 9 Distribution of $\lg \left(-\ln \left(\sigma_{1} / \sigma_{0}\right)\right)$ and $\lg (t)$ at different annealing temperatures in the a circumferential direction $\mathbf{b}$ generatrix direction $(t / \mathrm{min})$ 


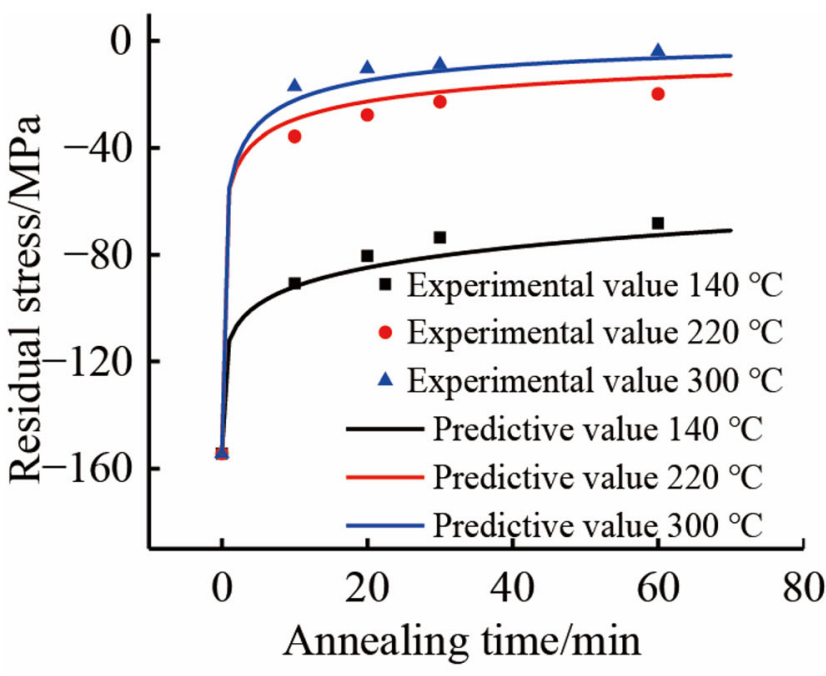

(a)

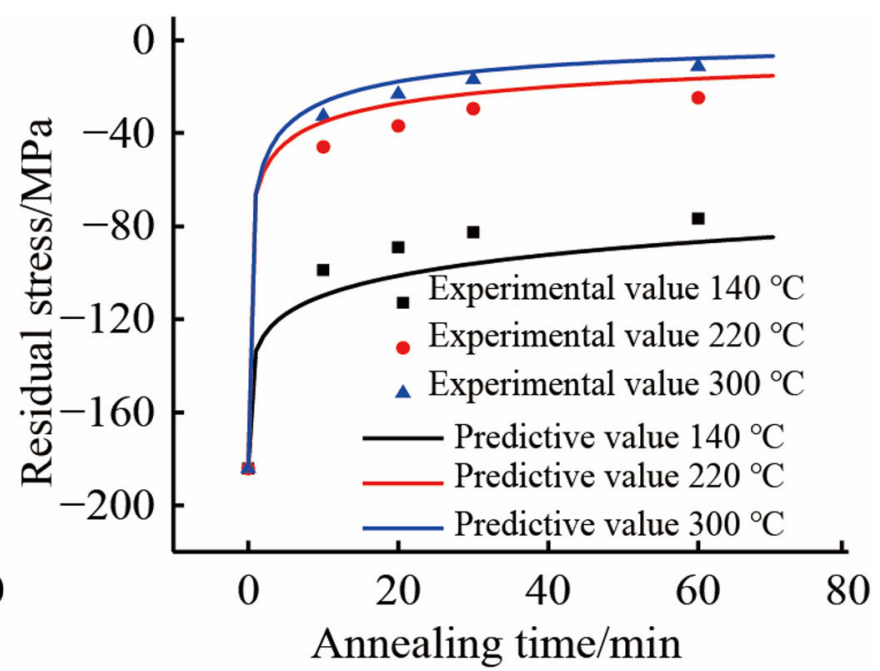

(b)

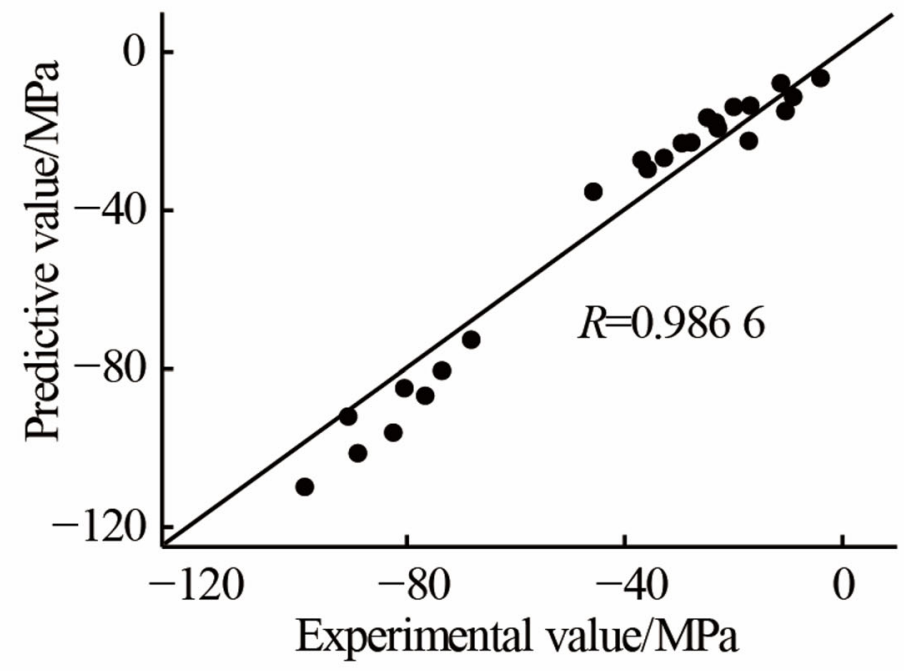

(c)

Fig. 10 Comparisons of the predicted and experimental residual stresses $\mathbf{a}$ in the circumferential direction, $\mathbf{b}$ in the generatrix direction, c correlation coefficient

\subsection{Verification of the residual-stress relaxation model}

To verify the accuracy of the established model, the residual stresses predicted by the model were compared with the experimental values, as shown in Figs. 10a and b. The prediction results at the tested annealing parameters agree well with the experimental results. Meanwhile, the correlation coefficient $R$ between the predicted and experimental residual stresses can be calculated using Eq. (8), where $E_{i}$ and $P_{i}$ are the experimental and predicted residual stresses, respectively, and $\bar{E}$ and $\bar{P}$ the mean values of $E_{i}$ and $P_{i}$, respectively. The experimental and predicted residual stresses are shown in Fig. 10c. The value of the correlation coefficient $R$ is 0.986 , and the absolute average error is $4.37 \mathrm{MPa}$. This indicates that the established model has a high accuracy in predicting the residualstress relaxation in the $5052 \mathrm{H} 32$ aluminum alloy spun heads during annealing treatment.

$R=\frac{\sum_{i=1}^{N}\left(E_{i}-\bar{E}\right)\left(P_{i}-\bar{P}\right)}{\sqrt{\sum_{i=1}^{N}\left(E_{i}-\bar{E}\right)^{2} \sum_{i=1}^{N}\left(P_{i}-\bar{P}\right)^{2}}}$.

\section{Conclusions}

The effects of the annealing parameters on the residualstress relaxation behavior and microstructures were examined in detail. The residual-stress relaxation 
mechanisms were also analyzed. A model was developed to describe the residual-stress relaxation features of the spun ellipsoidal heads during the annealing treatment. Some conclusions can be drawn as follows.

(i) Residual-stress relaxation mainly occurs during the early annealing stage. Increasing the annealing temperature decreases the residual stress. The change in the dislocation density is similar to that of the residual stress.

(ii) When the annealing temperature is less than 220 ${ }^{\circ} \mathrm{C}$, there is no obvious difference in the microstructures of the unannealed and annealed alloys. The residual stress decreases owing to the static recovery behavior. When the annealing temperature is approximately $300{ }^{\circ} \mathrm{C}$, static recrystallization and recovery occur simultaneously to reduce the residual stress further.

(iii) The correlation coefficient of the developed model is 0.9865 . The model can well describe the residual-stress relaxation features of spun ellipsoidal heads during annealing treatment. The optimized annealing temperature and time are approximately $300{ }^{\circ} \mathrm{C}$ and $30 \mathrm{~min}$, respectively.

Acknowledgments This work was supported by the National Natural Science Foundation of China (Grant No. 51775564), the Science and Technology Talent Promotion Project of Hunan Province (Grant No. 2020TJ-Q05), and the Fundamental Research Funds for the Central Universities of Central South University (Grant No. 2020zzts495).

Open Access This article is licensed under a Creative Commons Attribution 4.0 International License, which permits use, sharing, adaptation, distribution and reproduction in any medium or format, as long as you give appropriate credit to the original author(s) and the source, provide a link to the Creative Commons licence, and indicate if changes were made. The images or other third party material in this article are included in the article's Creative Commons licence, unless indicated otherwise in a credit line to the material. If material is not included in the article's Creative Commons licence and your intended use is not permitted by statutory regulation or exceeds the permitted use, you will need to obtain permission directly from the copyright holder. To view a copy of this licence, visit http://creativecommons. org/licenses/by/4.0/.

\section{References}

1. Xia QX, Xiao GF, Long $\mathrm{H}$ et al (2014) A review of process advancement of novel metal spinning. Int J Mach Tools Manuf 85:100-121

2. Xia QX, Xie SW, Huo YL et al (2008) Numerical simulation and experimental research on the multi-pass neck-spinning of nonaxisymmetric offset tube. J Mater Process Technol 206:500-508

3. Zhan M, Zhang T, Yang $\mathrm{H}$ et al (2016) Establishment of a thermal damage model for Ti-6Al-2Zr-1Mo-1V titanium alloy and its application in the tube rolling-spinning process. Int J Adv Manuf Technol 87:1345-1357
4. Music O, Allwood JM, Kawai K (2010) A review of the mechanics of metal spinning. J Mater Process Technol 210:3-23

5. Wu HX, Xu WC, Shan DB et al (2019) An extended GTN model for low stress triaxiality and application in spinning forming. J Mater Process Technol 263:112-128

6. Xu WC, Zhao XK, Shan DB et al (2016) Numerical simulation and experimental study on multi-pass staggered spinning of internally toothed gear using plate blank. J Mater Process Technol 229:450-466

7. Wang XK, Xia QX, Cheng XQ (2017) Deformation behavior of haynes230 superalloy during backward flow forming. Int J Precis Eng Manuf 18:77-83

8. Zhang HR, Zhan M, Guo J et al (2019) Forming the transverse inner rib of a curved generatrix part through power spinning. Adv Manuf 7:105-115

9. Yuan S, Xia QX, Long JC et al (2020) Study of the microstructures and mechanical properties of ZK61 magnesium alloy cylindrical parts with inner ribs formed by hot power spinning. Int J Adv Manuf Technol 111:851-860

10. Xia QX, Long JC, Zhu NY et al (2019) Research on the microstructure evolution of Ni-based superalloy cylindrical parts during hot power spinning. Adv Manuf 7(1):52-63

11. Lin YC, Qian SS, Chen XM et al (2019) Staggered spinning of thin-walled Hastelloy C-276 cylindrical parts: numerical simulation and experimental investigation. Thin Wall Struct 140:466-476

12. Sun W, You FH, Kong FT et al (2020) Effect of residual stresses on the mechanical properties of Ti-TiAl laminate composites fabricated by hot-pack rolling. Mater Charact 166:110394. https://doi.org/10.1016/j.matchar.2020.110394

13. Lin YC, Wu Q, He DG et al (2020) Effects of solution time and cooling rate on microstructures and mechanical properties of $2219 \mathrm{Al}$ alloy for a larger spun thin-wall ellipsoidal head. J Mater Res Technol 9(3):3566-3577

14. James M (2011) Residual stress influences on structural reliability. Eng Fail Anal 18:1909-1920

15. Song X, Fong KS, Oon SR et al (2014) Diametrical growth in the forward flow forming process: simulation, validation, and prediction. Int J Adv Manuf Technol 71:207-217

16. Zoghi H, Arezoodar AF, Sayeaftabi M (2012) Effect of feed and roller contact start point on strain and residual stress distribution in dome forming of steel tube by spinning at an elevated temperature. Proc IMechE Part B J Eng Manuf 226:1880-1890

17. Hu ZF, Wang CX (2012) Effect of tube spinning with subsequent heat-treatment on performance and microstructure evolution of T250 maraging steel. J Iron Steel Res Int 19(5):63-68

18. Chang SC, Wang CC, Huang C et al (2001) Fabrication of 2024 aluminum spun tube using a thermomechanical treatment process. J Mater Process Technol 108:294-299

19. Hui J, Feng ZX, Fan WX et al (2018) The influence of power spinning and annealing temperature on microstructures and properties of $\mathrm{Cu}-\mathrm{Sn}$ alloy. Mater Charact 144:611-620

20. Tsivoulas D, Quinta DA, Fonseca J et al (2015) Effects of flow forming parameters on the development of residual stresses in $\mathrm{Cr}$ Mo-V steel tubes. Mater Sci Eng A 624:193-202

21. Yu ZQ, Zhao YX, Du CY et al (2020) Study on flange-constrained spinning process for hemispherical aluminum alloy part. J Mater Process Technol 278:116515. https://doi.org/10.1016/j. jmatprotec.2019.116515

22. Lin YC, Qian SS, Chen XM et al (2020) Influences of feed rate and wall thickness reduction on the microstructures of thin-walled Hastelloy C-276 cylindrical parts during staggered spinning. Int J Adv Manufact Technol 106:3809-3821

23. Zhou Z, Gill A, Telang A et al (2014) Experimental and finite element simulation study of thermal relaxation of residual 
stresses in laser shock peened IN718 SPF superalloy. Exp Mech 54:1597-1611

24. Ren XD, Zhou WF, Xu SD et al (2015) Iron GH2036 alloy residual stress thermal relaxation behavior in laser shock processing. Opt Laser Technol 74:29-35

25. Wang Z, Chen YH, Jiang CH (2011) Thermal relaxation behavior of residual stress in laser hardened 17-4PH steel after shot peening treatment. Appl Surf Sci 257(23):9830-9835

26. Xie XF, Jiang WC, Luo $Y$ et al (2017) A model to predict the relaxation of weld residual stress by cyclic load: Experimental and finite element modeling. Int J Fatigue 95:293-301

27. Sembiring J, Amanov A, Pyun YS (2020) Artificial neural network-based prediction model of residual stress and hardness of nickel-based alloys for UNSM parameters optimization. Mater Today Commun 25:101391. https://doi.org/10.1016/j.mtcomm. 2020.101391

28. Jagtap P, Chason E (2020) A unified kinetic model for stress relaxation and recovery during and after growth interruptions in polycrystalline thin films. Acta Mater 193:202-209

29. Juijerm P, Altenberger I (2006) Residual stress relaxation of deep-rolled $\mathrm{Al}-\mathrm{Mg}-\mathrm{Si}-\mathrm{Cu}$ alloy during cyclic loading at elevated temperatures. Scripta Mater 55:1111-1114

30. Robinson JS, Pirling T, Truman CE et al (2017) Residual stress relief in the aluminium alloy 7075. Mater Sci Technol 33(15):1765-1775

31. Wang JT, Zhang YK, Chen JF et al (2017) Effect of laser shock peening on the high-temperature fatigue performance of 7075 aluminum alloy. Mater Sci Eng A 704:459-468

32. Chen M, Liu H, Wang L et al (2018) Investigation on the thermostability of residual stress and microstructure in shot peened SAF 2507 duplex stainless steel. Vacuum 153:145-153

33. Madariaga A, Aperribay J, Arrazola PJ et al (2017) Effect of thermal annealing on machining-induced residual stresses in Inconel 718. J Mater Eng Perform 26(8):3728-3738

34. Lin YC, Chen JY, He DG et al (2020) Marginal-restraint mandrel-free spinning process for thin-walled ellipsoidal heads. Adv Manuf 8:189-203

35. Chen JY, Lin YC, Pang GD et al (2020) Effects of spinning parameters on microstructures of ellipsoidal heads during marginal-restraint mandrel-free spinning. Adv Manuf 8:457-472

36. Chen MS, Wang GQ, Li HB et al (2019) Annealing treatment methods and mechanisms for refining mixed and coarse grains in a solution treatment nickel-based superalloy. Adv Eng Mater 21:1900558. https://doi.org/10.1002/adem.201900558

37. Chen XM, Lin YC, Wu F (2017) EBSD study of grain growth behavior and annealing twin evolution after full recrystallization in a nickel-based superalloy. J Alloys Compd 724:198-207

38. Birosca S, Liu G, Ding R et al (2019) The dislocation behaviour and GND development in a nickel based superalloy during creep. Int J Plasticity 118:252-268

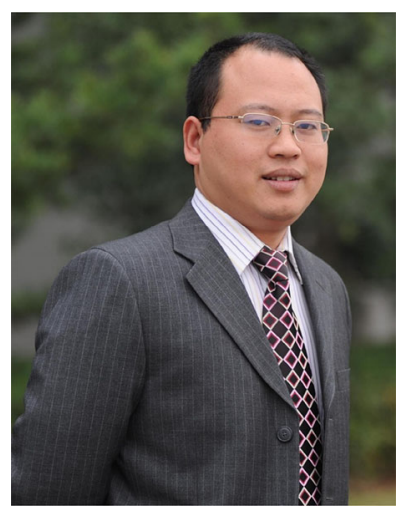

Yong-Cheng Lin is a professor in the School of Mechanical and Electrical Engineering, Central South University, China. He received his B.S. (2000) and M.S. (2003) degrees from Liaoning University of Petroleum and Chemical Technology, China and his Ph.D. (2006) from Tianjin University, China; all his degrees are in Mechanical Engineering. He joined the faculty of Central South University in 2006. He is also a member of the State Key Laboratory of High Performance Complex Manufacturing. His current research interests are experimental, theoretical, and simulation investigations on hot deformation processing-structure-property relationship of alloys. He has jointly published more than 200 international journal papers as well as two books. He has gained more than 12000 self-exclusive citations. Moreover, he has obtained more than 30 patents in China and received four science and technology awards from Hunan Province, China. He is also a member of the editorial board of more than 10 international journals including Materials and Design, Journal of Materials: Design and Applications, Materials Science and Engineering A, Materials, Journal of Materials Engineering and Performance, and Advanced Engineering Materials. Additionally, he has been a chair and member of technical and organizing committees for more than 90 international academic conferences. Further details about him can be found at http://faculty.csu.edu.cn/yclin

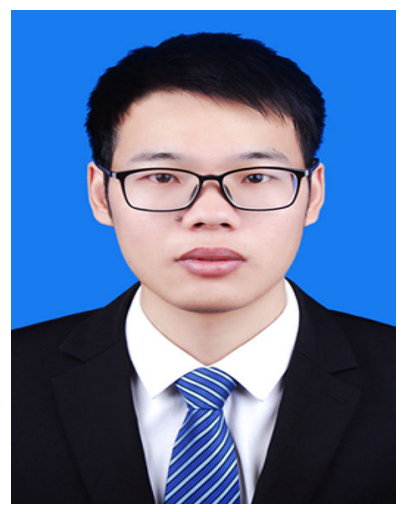

Jiang-Shan Zhu is an M.S. candidate of the School of Mechanical and Electrical Engineering, Central South University, China. He obtained his B.S. degree in Mechanical Engineering from Central South University, China. His main research interest is on advanced spinning processing technology of high-quality metal parts.is an M.S. candidate of the School of Mechanical and Electrical Engineering, Central South University, China. He obtained his B.S. degree in Mechanical Engineering from Central South University, China. His main research interest is on advanced spinning processing technology of high-quality metal parts. 


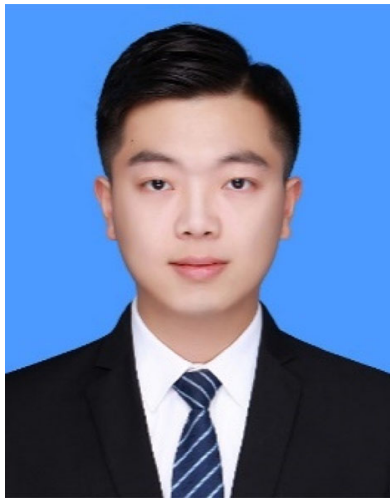

Jia-Yang Chen is an M.S. candidate of the School of Mechanical and Electrical Engineering, Central South University, China. He obtained his B.S. degree in Materials Engineering from Xiangtan University, China. His main research interest is on advanced spinning processing technology of high-quality metal parts.

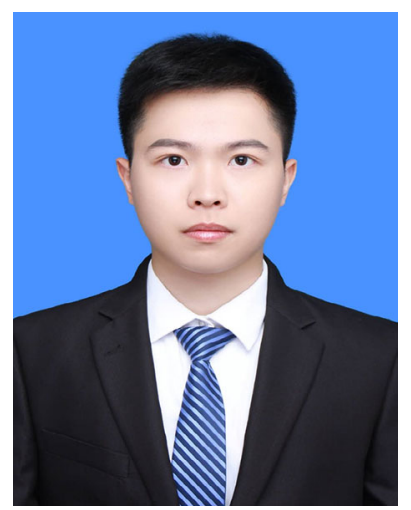

Jun-Quan Wang is an M.S. candidate of the School of Mechanical and Electrical Engineering, Central South University, China. He obtained his B.S. degree in Mechanical Engineering from Huazhong Agricultural University, China. His main research interest is on advanced spinning processing technology of high-quality metal parts. 